\title{
First Report of Two Species of Genus Raymunida (Crustacea: Decapoda: Anomura) from Korea
}

\author{
Sanghui Lee, Won Kim* \\ School of Biological Sciences, Seoul National University, Seoul 151-747, Korea
}

\begin{abstract}
Two species of squat lobsters, Raymunida formosanus Lin, Chan and Chu, 2004 and Raymunida lineata Osawa, 2005, are newly added to the Korean decapod fauna. The genus Raymunida Macpherson and Machordom, 2000 is also reported for the first time in Korea. It differs morphologically from other Korean genera, Munida and Paramunida, in having the first to third pereopods with epipods and the carpus of the third maxilliped with a distal spine on flexor margin. Illustrations and pictures of these two species are provided with descriptions, and the key to the species of Korean Munidids is also provided.
\end{abstract}

Keywords: Korean fauna, Anomura, Munididae, Raymunida, Raymunida formosanus, Raymunida lineata

\section{INTRODUCTION}

The family Munididae Ahyong, Baba, Macpherson and Poore, 2010 is the most diverse family in the galatheoids and includes 421 species in 20 genera worldwide (Macpherson and Baba, 2011). However, only 2 species of 2 genera have been reported from the Korean fauna: Munida japonica Stimpson, 1858 and Paramunida scabra (Henderson, 1885) (see Kim, 1973). The genus Raymunida Macpherson and Machordom, 2000 belonging to the family Munididae accommodates 12 species (Osawa, 2012). It is separated from the genus Munida Leach, 1820 by Macpherson and Machordom (2000) based on morphological characters: 1 ) first to third pereopods bearing epipods; 2) frontal margin of carapace with one spine; 3 ) third maxilliped with carpus having one spine at flexor distal margin. As a result of study on Korean galatheoids fauna, Raymunida formosanus Lin, Chan and Chu, 2004 and Raymunida lineata Osawa, 2005 are recorded for the first time in Korea. They were collected from southern coast of Jeju Island. Of these, the northern range of geographical distribution of $R$. formosanus is extended from Taiwan to Jeju Island in Korea. Both species differ in the number of spines on anterior branchial regions, spination of antennal articles, and thickness of the first pereopod. In this study, illustrations, including photographs, and descriptions are provided and the key to the species of Korean munidids is also provided.

\section{MATERIALS AND METHODS}

The specimens examined in this study were preserved in $70 \%$ ethyl alcohol. All drawings were prepared by using camera lucida on a Nikon SMZ800 (Nikon, Tokyo, Japan). All characters were measured using an analog caliper diaMax 4112102 (Wiha, Schonach, Germany) to the nearest $0.1 \mathrm{~mm}$. The terminology used follows Baba et al. (2011). The abbreviation CL refers to the carapace length measured across the middle of the carapace from the anterior border excluding rostrum to the posterior border. Higher classification follows Ahyong et al. (2011). The specimens examined in the present study are deposited in the Marine Arthropod Depository Bank of Korea (MADBK), Seoul National University.

\section{SYSTEMATIC ACCOUNTS}

Order Decapoda Latreille, 1802

Superfamily Galatheoidea Samouelle, 1819

1*Family Munididae Ahyong, Baba, Macpherson and Poore, 2010

Korean name: ${ }^{1 *}$ 바늘이마새우붙이과 (신칭)

(C) This is an Open Access article distributed under the terms of the Creative Commons Attribution Non-Commercial License (http://creativecommons.org/ licenses/by-nc/3.0/) which permits unrestricted non-commercial use, distribution, and reproduction in any medium, provided the original work is properly cited.

pISSN 2234-6953 eISSN 2234-8190
*To whom correspondence should be addressed

Tel: 82-2-880-6695, Fax: 82-2-872-1993

E-mail: wonkim@plaza.snu.ac.kr 


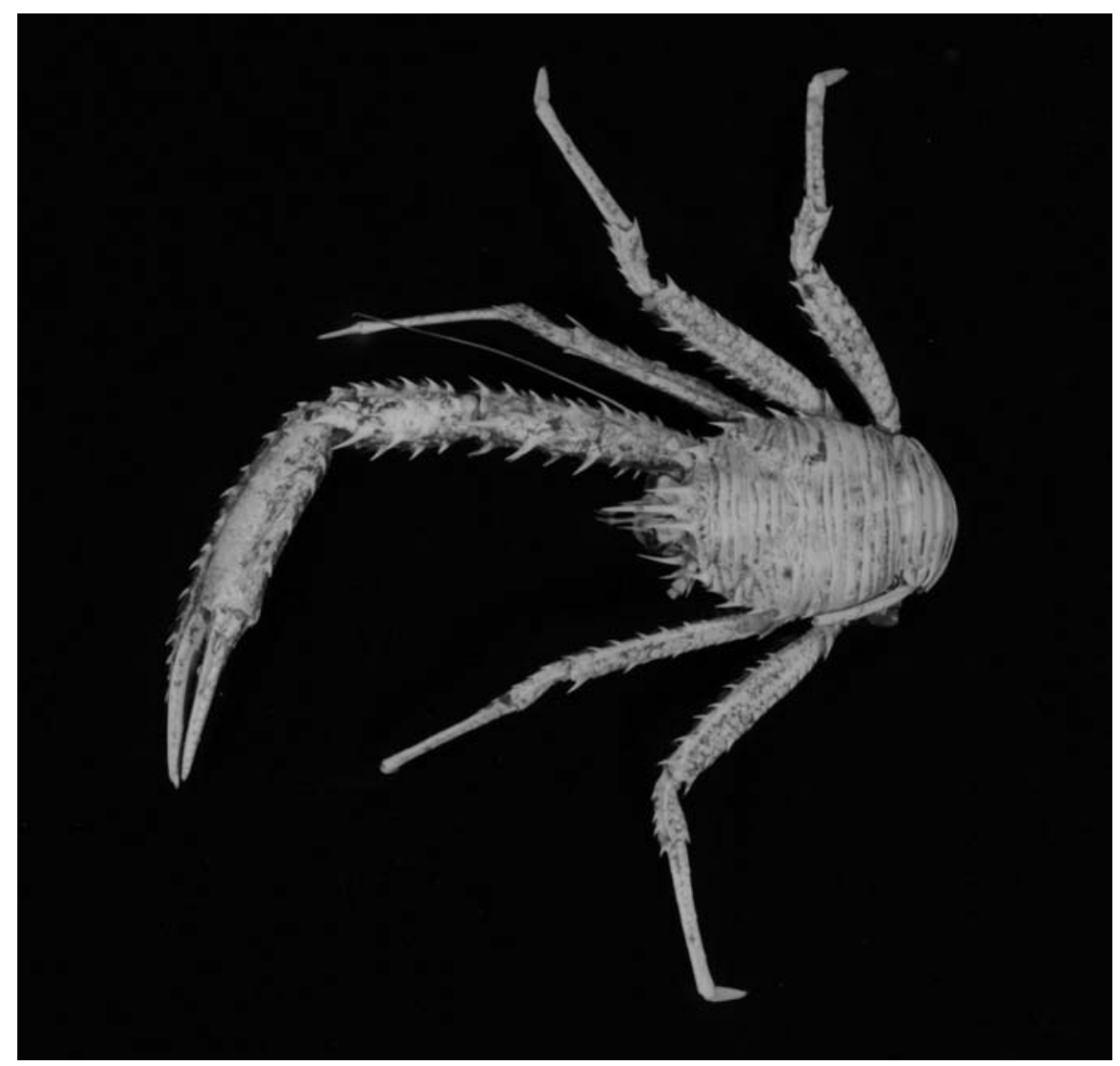

Fig. 1. Raymunida formosanus Lin, Chan and Chu, 2004, male (CL $18.4 \mathrm{~mm})$. Dorsal view. CL, carapace length from anterior border excluding rostrum to posterior border.

1*Genus Raymunida Macpherson and Machordom, 2000

\section{${ }^{2 *}$ Raymunida formosanus Lin, Chan and Chu, 2004}

(Figs. 1-3)

Raymunida formosanus Lin, Chan and Chu, 2004: 149, figs. 1-3 (type locality: Taiwan, Tai-Shi fishing port, I-Lan County, commercial trawler, about $300 \mathrm{~m}$ ); Ahyong and Poore, 2004: 70, fig. 17; Poore, 2004: 239, fig. 66c, d; Baba, 2005: 307; Baba et al., 2008: 179; 2009: 291, figs. $265,266$.

Material examined. 2 ð Island, Seogwipo-si, 10 Oct 1970.

Description. Carapace (Figs. 1, 2A), excluding rostrum, as long as broad; dorsal surface with distinct transverse striae; having 5 pairs of epigastric spines, with 1 pair of parahepatic spines and postcervical spines. Anterior branchial region having 4 to 5 spines. Frontal margin slightly oblique, having 1 small spine. Lateral margins somewhat convex, each with
6 spines: 2 anterolateral, 2 anterobranchial, 2 posterobranchial. Cervical groove distinct. Rostrum spiniform, 0.4 times as long as remaining carapace length. Supraocular spines 0.5 times as long as rostrum length, subparallel.

Pterygostomian flaps slightly rugose, unarmed.

Thoracic sternites (Fig. 2B) 0.8 times as long as broad, bearing distinct medial groove, lateral limits expanded posteriorly.

Abdominal somites 2, 3 (Figs. 1, 2A) each having 2 uninterrupted transverse ridges.

Eyes (Fig. 2A) subcylindrical, slightly expanded distally, overreaching supraocular spine.

Antennular article 1 (Fig. 2C) having 2 well-developed distal spines: 1 small distomesial, 1 well-developed distolateral; bearing 2 lateral spines: 1 short proximal, 1 prominent distal, which slightly reaching tip of distolateral spine.

Antennal article 1 (Fig. 2C) bearing 1 distomesial spine, slightly overreaching distal margin of antennal article 3. Antennal article 2 having 2 distal spines, distomesial spine 

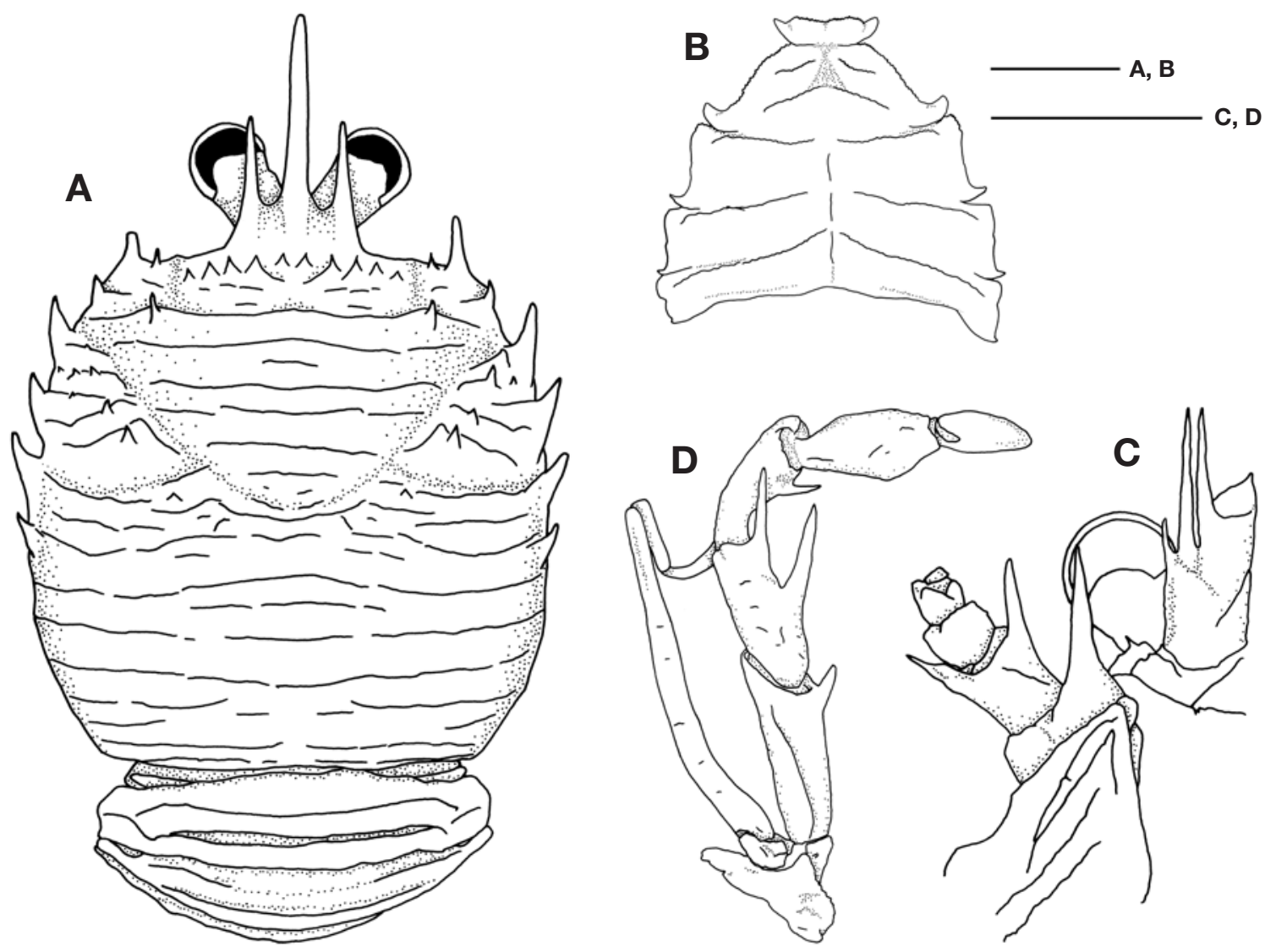

Fig. 2. Raymunida formosanus Lin, Chan and Chu, 2004, male (CL $18.4 \mathrm{~mm}$ ). A, Carapace, anterior part of abdomen (setae omitted); B, Thoracic sternites; C, Anterior right part of cephalothorax, ventral view, showing antennular and antennal peduncles (setae omitted); D, Right maxilliped 3 (setae omitted). $C L$, carapace length from anterior border excluding rostrum to posterior border. Scale bars: $A-D=5 \mathrm{~mm}$.

larger than distolateral spine. Antennal articles 3, 4 unarmed.

Maxilliped 3 (Fig. 2D) with ischium bearing 1 distal spine on flexor margin. Merus as long as ischium, with 2 prominent spines on flexor margin, distal spine slightly slender. Carpus having 1 spine on distal end of flexor margin. Propodus and dactylus unarmed. Exopod overreaching distal end of merus (excluding distal spine).

Pereopod 1 (Figs. 1, 3A, B) stout, squamous and spinose. Merus 3.9 times as long as broad, having irregular spines on extensor and flexor margins. Carpus 2.3 times as long as broad, bearing irregular row of spines on mesial and lateral margins, dorsal surface with some spines. Palm twice as long as broad, about 1.5 times as long as movable finger, mesial and lateral margins having irregular row of spines. Fingers having 1 distinct longitudinal ridge on dorsal and ventral sides, bearing irregular row of spines; fixed finger curved; movable finger with cutting edge having 1 large tooth on proximal third.

Pereopod 2(Fig. 3C) slender. Ischium having 1 small spine on distoflexor margin. Merus 6.6 times as long as broad, armed with row of spines on extensor margin, flexor margin bearing row of spines on distal third. Carpus 2.2 times as long as broad, with 4 spines on extensor margin. Propodus 3.1 times longer than dactylus, 10.1 times as long as broad, flexor margin armed with 5 movable spines including distal pair: 1 distolateral, 1 distomesial (distomesial spine not illustrated). Dactylus short, curving distally, having 7 movable spines on flexor margin. Pereopod 3 (Fig. 3D) with ischium having 1 small spine on distoflexor margin; merus 4.5 times as long as broad, having row of spines on extensor margin, flexor margin bearing row of spines on distal third; carpus twice as long as broad, bearing 4 spines on extensor margin; propodus 8.8 times as long as broad, flexor margin bearing 5 movable spines including distal pair: 1 distolateral, 1 distomesial (distomesial spine not illustrated); dactylus short, curving distally, having six movable spines on flexor margin. Pereopod 4 (Fig. 3E) with ischium unarmed; merus 4.3 times as long as broad, extensor margin having row of spines; car- 

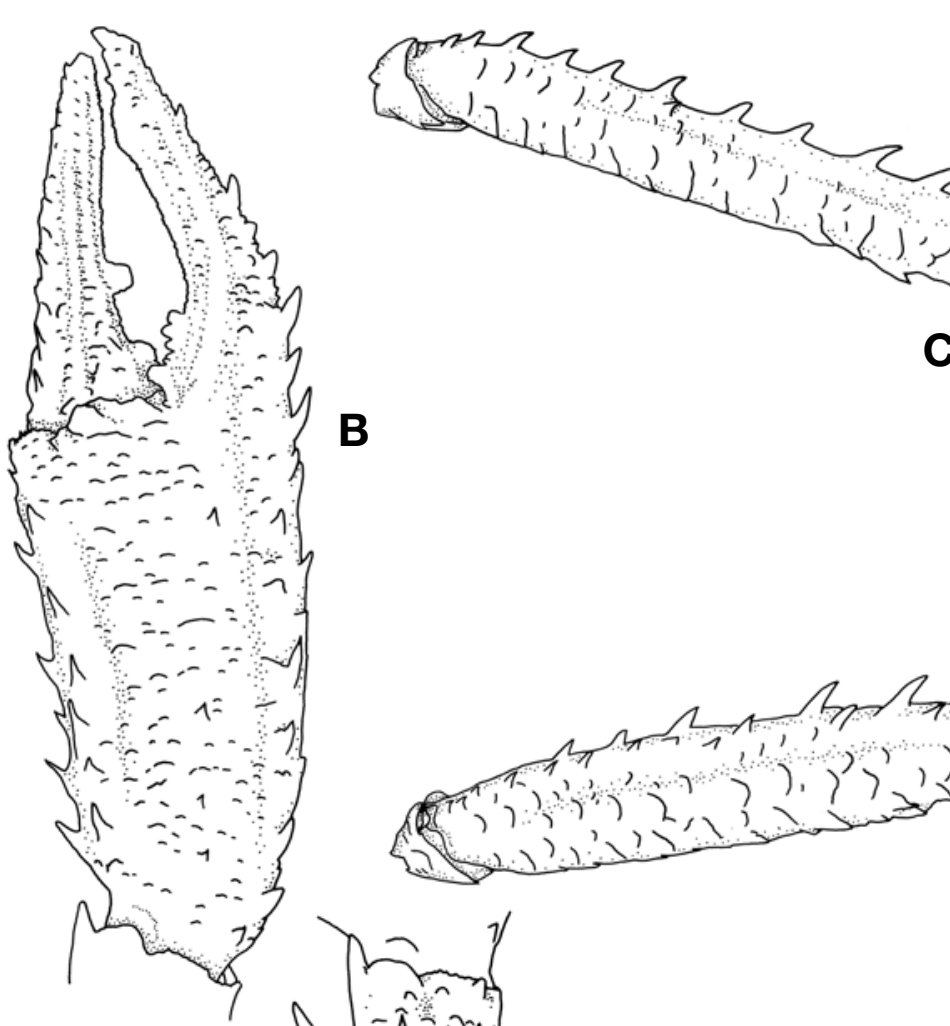

$\mathbf{B}$

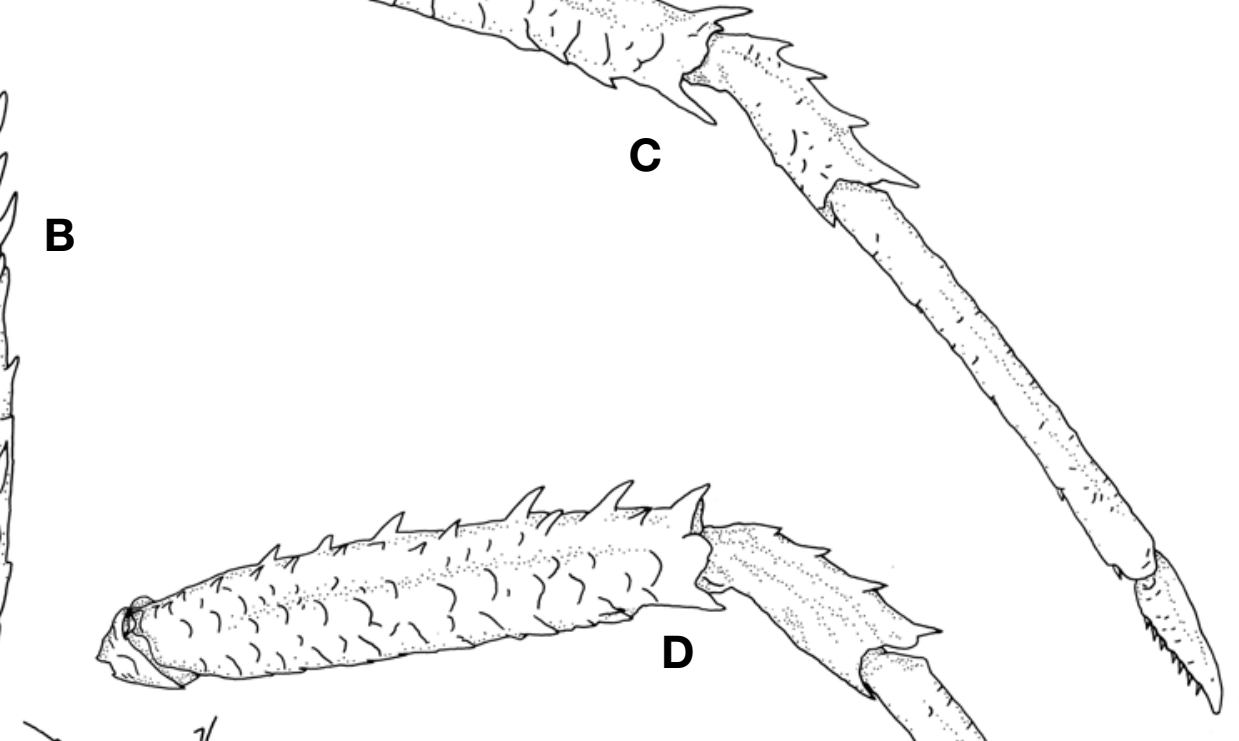

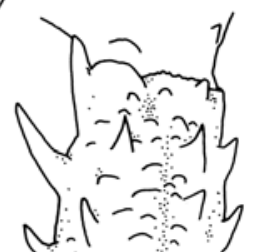

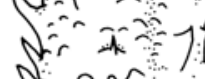

\section{(19}

A
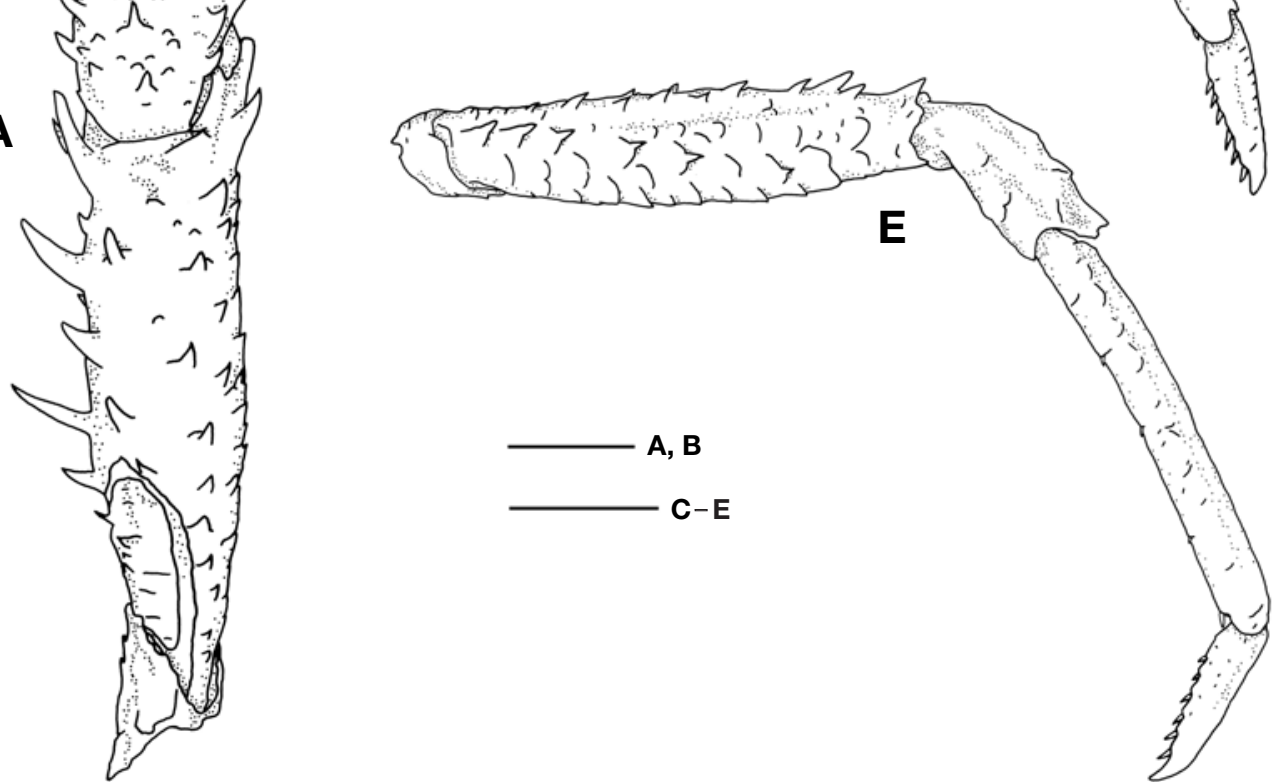

E

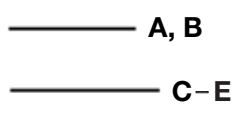

Fig. 3. Raymunida formosanus Lin, Chan and Chu, 2004, male (CL $18.4 \mathrm{~mm}$ ). A, Right pereopod 1, ischium, merus, and carpus (setae omitted); B, Same, chela (setae omitted); C, Right pereopod 2 (setae omitted); D, Right pereopod 3 (setae omitted); E, Right pereopod 4 (setae omitted). CL, carapace length from anterior border excluding rostrum to posterior border. Scale bars: A$\mathrm{E}=5 \mathrm{~mm}$. 


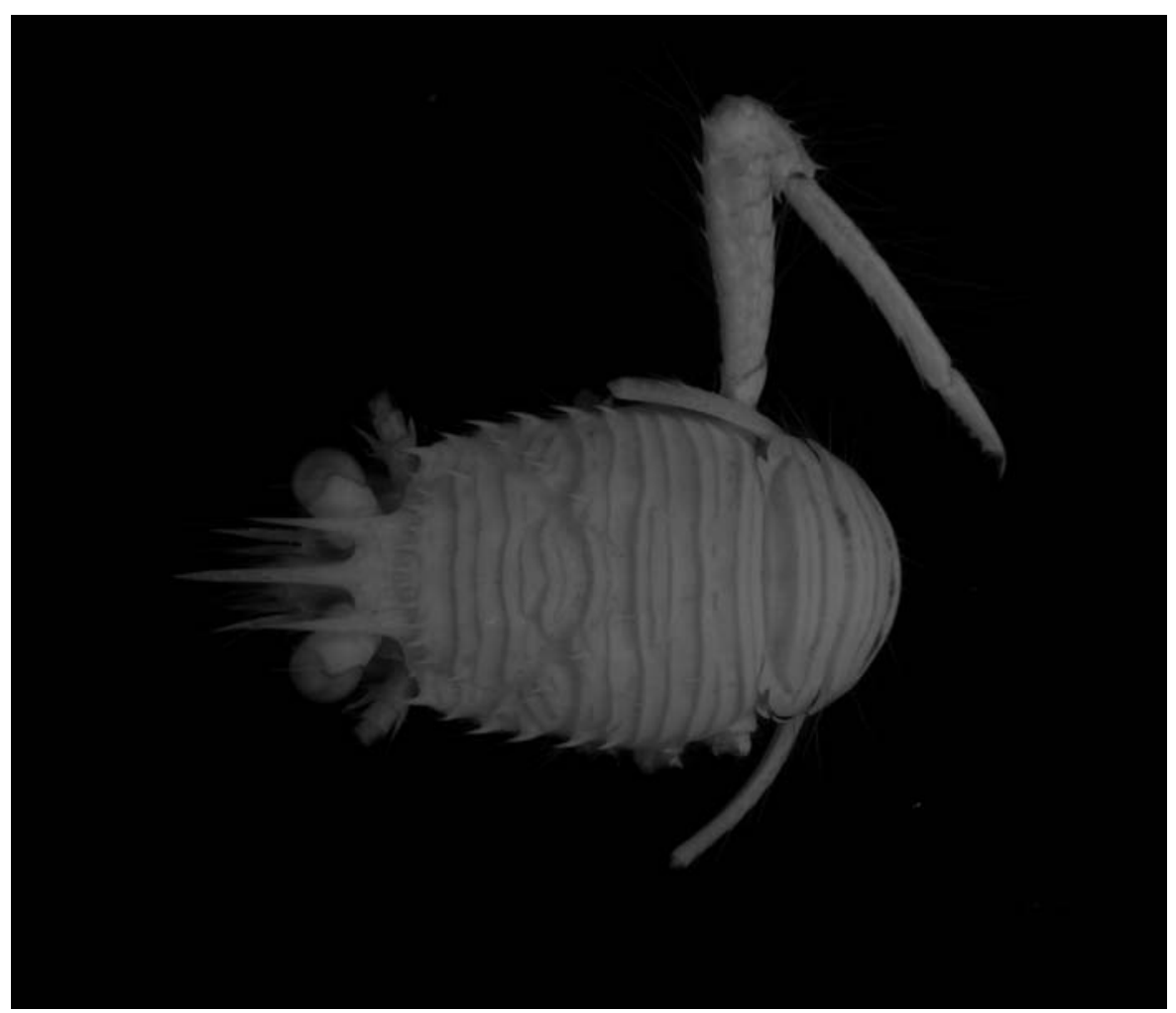

Fig. 4. Raymunida lineata Osawa, 2005, male (CL $6.4 \mathrm{~mm}$ ). Dorsal view. $\mathrm{CL}$, carapace length from anterior border excluding rostrum to posterior border.

pus 1.8 times as long as broad, extensor margin bearing 4 low spines; propodus 7.8 times as long as broad, flexor margin bearing 5 movable spines including distal pair: 1 distolateral, 1 distomesial (distomesial spine not illustrated); dactylus short, curving distally, having 6 movable spines on flexor margin.

Distribution. Taiwan, New South Wales of Australia and Korea.

Remarks. Raymunida formosanus has been recorded from Taiwan and eastern Australia (Baba et al., 2009). Thus, the present specimens from Jeju Island are the most northern record of this species.

Raymunida formosanus is morphologically similar to $R$. confundens Macpherson and Machordom, 2001. They share the following characteristics: the second antennal article is unarmed on mesial margin, and the frontal margin has one small spine. However, the $R$. formosanus can be distinguished by the following characteristics. 1) In the present species, the anterior branchial region bears four to five spines, but $R$. confundens, has four spines. 2) The first pereopod is robuster than that of $R$. confundens. 3) The second to fourth pereopods bear distinct squamae, while in $R$. confundens, distinct squamae absent (Lin et al., 2004).

The present specimens agreed well with the original description (Lin et al., 2004) except for the length of the distomesial spine on antennal article 1. Lin et al. (2004) mentioned that the spine reached the first antennular article. In addition, their illustration (Lin et al. 2004, fig. 1b, f) indicated that distomesial spine on antennal article 1 overreached distal margin of antennal article 4. However, in examined specimens, the spine slightly reached distal margin of antennal article 3 . Such difference seems to be a morphological variation of the species.

${ }^{1 *}$ Raymunida lineata Osawa, 2005 (Figs. 4-6)

Munida elegantissima: Baba, 1969: 37, figs. 3, 4.

Galathea sp. 1: Gosliner et al., 1996: 226, fig. 821.

Raymunida lineata Osawa, 2005: 92, figs. 3-6 (type locality: Izu Peninsula, Shizuoka Prefecture, 20 m); 2012: 143; Baba et al., 2008: 180.

Material examined. $1 \sigma^{\nearrow}$ (CL $\left.6.4 \mathrm{~mm}\right)$, Korea, Jeju Island,

Korean name: ${ }^{1 *}$ 세로줄가시마디새우붙이 (신칭) 

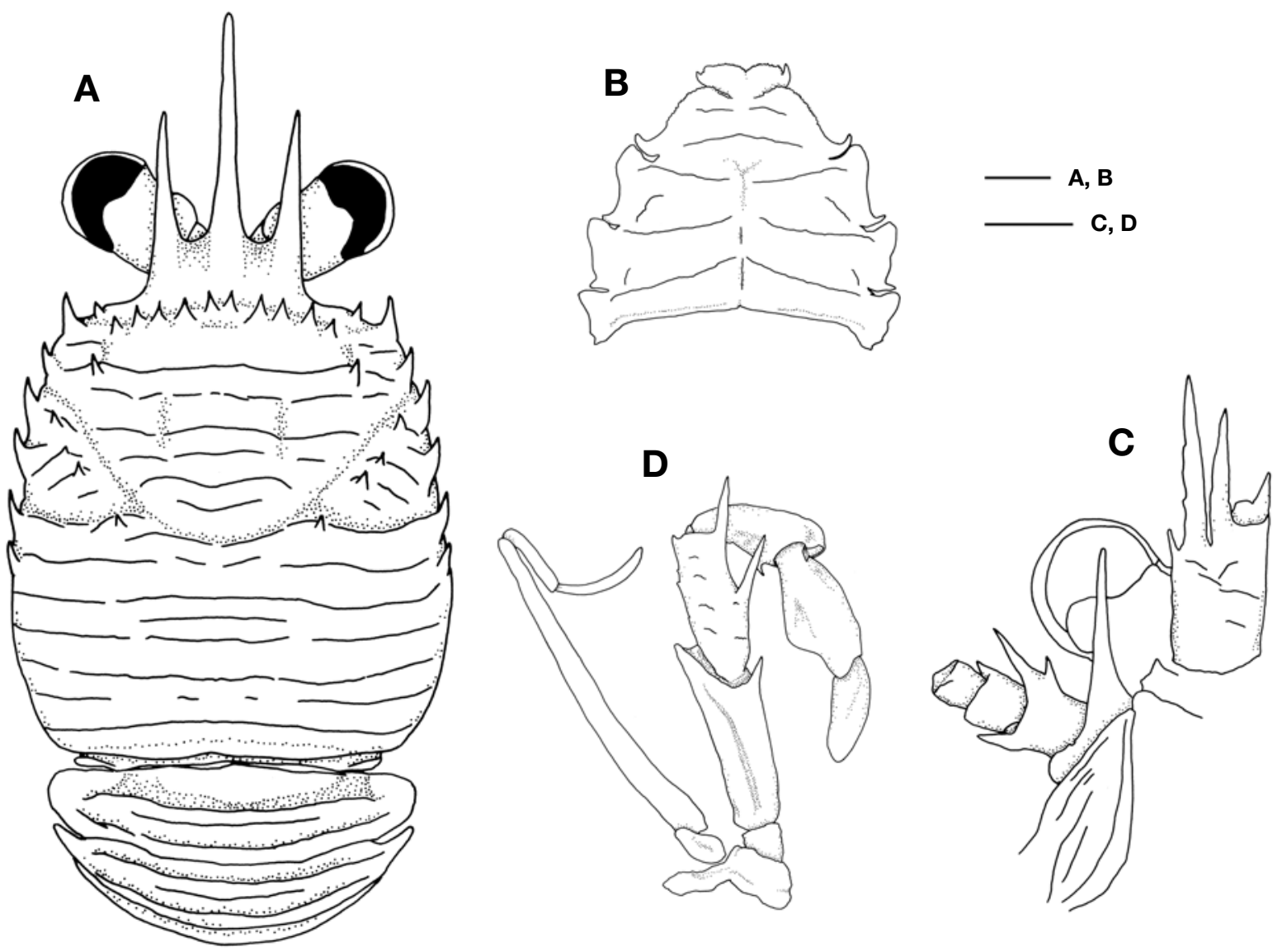

Fig. 5. Raymunida lineata Osawa, 2005, male (CL $6.4 \mathrm{~mm}$ ). A, Carapace, anterior part of abdomen (setae omitted); $B$, Thoracic sternites; C, Anterior right part of cephalothorax, ventral view, showing antennular and antennal peduncles (setae omitted); D, Right maxilliped 3 (setae omitted). CL, carapace length from anterior border excluding rostrum to posterior border. Scale bars: A$\mathrm{D}=1 \mathrm{~mm}$.

Seogwipo-si, Songsan-dong, 8 Mar 2002.

Description. Carapace (Figs. 4, 5A), excluding rostrum, slightly longer than broad; dorsal surface with distinct transverse striae; having 5 pairs of epigastric spines, with 1 pair of parahepatic spines and postcervical spines. Anterior branchial region having 3 spines. Frontal margin slightly oblique, having 1 small spine. Lateral margin slightly convex, each with 6 spines: 2 anterolateral, 2 anterobranchial, 2 posterobranchial. Cervical groove distinct. Rostrum spiniform, 0.5 times as long as carapace length. Supraocular spines 0.6 times as long as rostrum length, subparallel.

Pterygostomian flap slightly rugose, unarmed.

Thoracic sternites (Fig. 5B) 0.8 times as long as broad, bearing distinct medial groove, lateral limits expanded posteriorly; sternites 5, 6 having distinct oblique ridges on lateral part.

Abdominal somites 2, 3 (Figs. 4, 5A) each having 2 uninterrupted and transverse ridges.
Eyes (Fig. 5A) subcylindrial, slightly expanded distally, slightly reaching supraocular spine.

Antennular article 1 (Fig. 5C) having 2 well-developed distal spines: 1 small distomesial, 1 well-developed distolateral; bearing 2 lateral spines: 1 short proximal, 1 prominent distal (overreaching distolateral spine).

Antennal article 1 (Fig. 5C) bearing 1 distomesial spine, overreaching distal margin of antennal article 4. Antennal article 2 having 2 distal spines, distomesial spine larger than distolateral spine, mesial margin having small spine. Antennal article 3 bearing 1 small distomesial spine. Antennal article 4 unarmed.

Maxilliped 3(Fig. 5D) with ischium bearing 1 distal spine on flexor margin. Merus as long as ischium, with 2 prominent spines on flexor margin. Carpus having 1 spine on distal end of flexor margin. Propodus and dactylus unarmed. Exopod overreaching distal end of merus (excluding distal spine).

Pereopod 1 (Fig. 6A, B) slender, squamous, setose and 


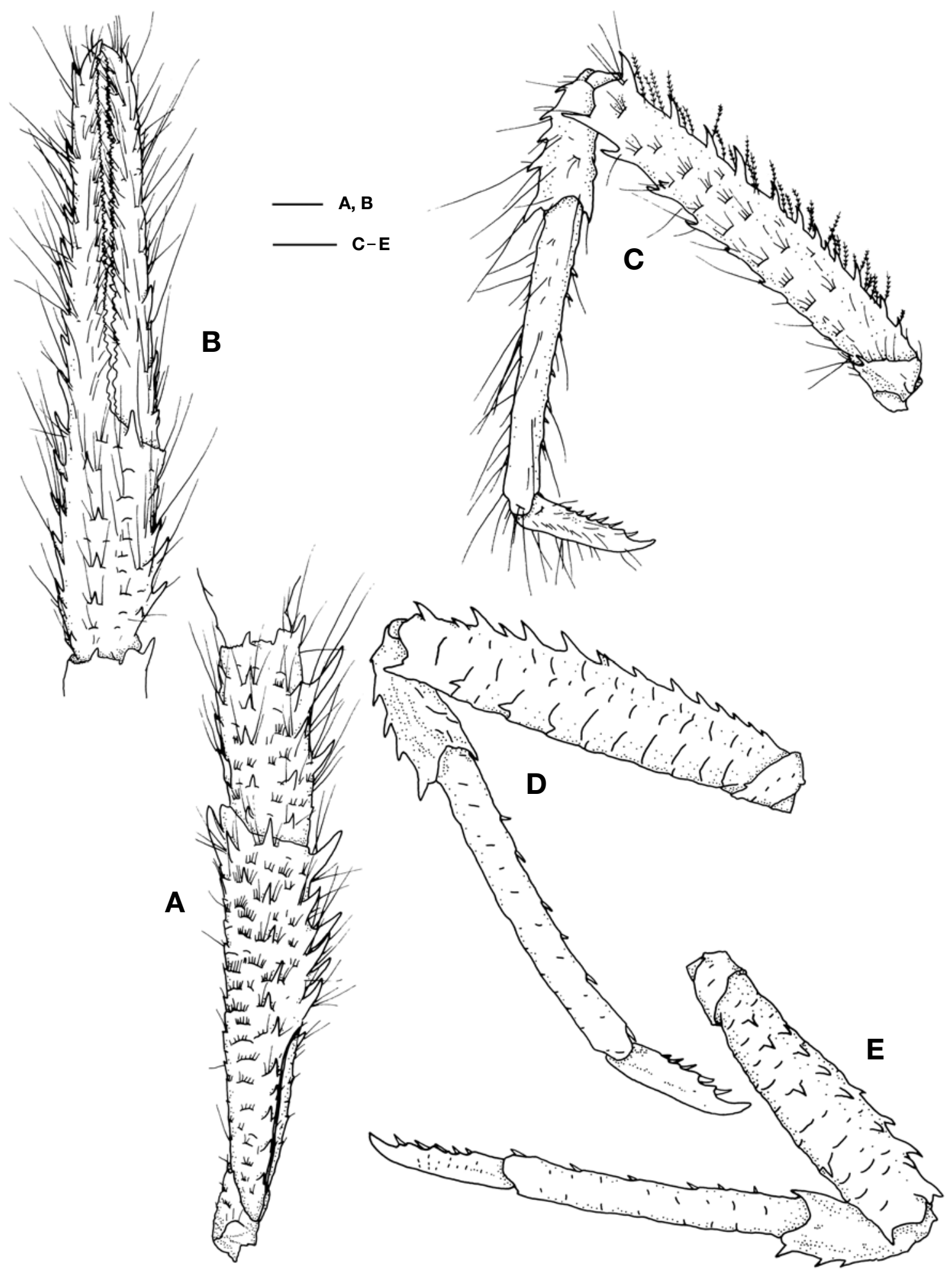

Fig. 6. Raymunida lineata Osawa, 2005, male (CL $6.4 \mathrm{~mm}$ ). A, Left pereopod 1, ischium, merus, and carpus; B, Same, chela; C, Left pereopod 2; D, Left pereopod 3 (setae omitted); E, Right pereopod 4 (setae omitted). CL, carapace length from anterior border excluding rostrum to posterior border. Scale bars: $A-E=1 \mathrm{~mm}$. 
spinose. Merus 4.8 times as long as broad, having irregular spines on flexor margin, extensor margin having 1 prominent spine. Carpus 2.3 times as long as broad, bearing row of irregular spines on mesial and lateral margins, mesial margin with well-developed spines, dorsal surface with some spines bearing short setae. Palm 1.6 times as long as broad, 0.6 times as long as movable finger, mesial and lateral margins having row of spines. Finger bearing row of spines; cutting edge having saw-shaped teeth.

Pereopod 2 (Fig. 6C) slender. Ischium having 1 small spine on distoflexor margin. Merus 6.3 times as long as broad, extensor margin armed with row of spines, having plumose setae; flexor margin bearing row of spines on distal half, and spine sizes increasing distally. Carpus 2.5 times as long as broad, 5 spines on extensor margin. Propodus 3 times longer than dactylus, 8.7 times as long as broad, flexor margin armed with 9 movable spines including distal pair: 1 distolateral, 1 distomesial (distomesial spine not illustrated). Dactylus short, curving distally, having 6 movable spines on flexor margin. Pereopod 3 (Fig. 6D) with ischium having 1 small spine on distoflexor margin; merus 4.5 times as long as broad, having row of spines on extensor margin, flexor margin bearing row of spines on distal third; carpus 2.5 times as long as broad, bearing 5 spines on extensor margin; propodus 8.5 times as long as broad, flexor margin bearing 7 movable spines including distal pair: 1 distolateral, 1 distomesial (distomesial spine not illustrated); dactylus short, curving distally, having 5 movable spines on flexor margin. Pereopod 4 (Fig. 6E) with ischium unarmed; merus 3.9 times as long as broad, extensor margin having row of spines; carpus 2.3 times as long as broad, extensor margin bearing 4 low spines; propodus 8.1 times as long as broad, flexor margin bearing 7 movable spines including distal pair: 1 distolateral, 1 distomesial (distomesial spine not illustrated); dactylus short, curving distally, having 6 movable spines on flexor margin.

Distribution. Indonesia, Japan and Korea.

Remarks. Osawa (2005) described that the brachial margins of Raymunida lineata are moderately convex. However, the present specimen has subparallel branchial margins. Nevertheless, the present specimen agreed well with the type description in other diagnostic aspects.

According to original description of Osawa (2005), Raymunida lineata is closely related to $R$. elegantissima (De Man, 1902) in antennal article 2 armed with one small spine on mesial margin, and maxilliped 3 with unarmed merus on extensor margin. However, the present species differs in the following points from $R$. elegantissima: thoracic sternites 5 , 6 each having distinct oblique ridges on lateral parts, while in R. elegantissima, having faint, short ridges on lateral parts; antennal article 1 overreaching distal margin of antennal arti- cle 4 , but in $R$. elegantissima, antennal article 1 reaching distal margin of antennal article 3 .

\section{Key to the species of Korean munidids}

1. Carpus of maxilliped 3 unarmed on distal end of flexor

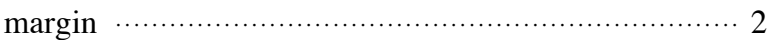

- Carpus of maxilliped 3 having one spine on distal end of

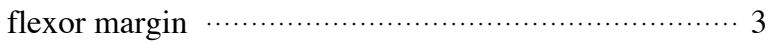

2. Carapace with distinct transverse striae; rostrum overreaching end of eye …....................... Munida japonica

- Carapace with indistinct transverse striae; rostrum not reaching end of eye .................. Paramunida scabra

3. Antennal article 2 unarmed on mesial margin; antennal article 3 unarmed …............. Raymunida formosanus

- Antennal article 2 having small spine on mesial margin; antennal article 3 bearing one small distomesial spine....

Raymunida lineata

\section{ACKNOWLEDGMENTS}

This work was supported by a grant from the National Institute of Biological Resources (NIBR), funded by the Ministry of Environment (MOE) of the Republic of Korea (NIBR No. 2013-02-001), and Marine Biotechnology Program Funded by Ministry of Oceans and Fisheries of Korean Government.

\section{REFERENCES}

Ahyong ST, Baba K, Macpherson E, Poore GCB, 2010. A new classification of the Galatheoidea (Crustacea: Decapoda: Anomura). Zootaxa, 2676:57-68.

Ahyong ST, Lowry JK, Alonso M, Bamber RN, Boxshall GA, Castro P, Gerken S, Karaman GS, Goy JW, Jones DS, Meland K, Rogers DC, Svavarsson J, 2011. Subphylum Crustacea Brünnich, 1772. In: Animal biodiversity: an outline of higher-level classification and survey of taxonomic richness (Ed., Zhang ZQ). Zootaxa, 3148:165-191.

Ahyong ST, Poore GCB, 2004. Deep-water Galatheidae (Crustacea: Decapoda: Anomura) from southern and eastern Australia. Zootaxa, 472:1-76.

Baba K, 1969. New addition to the galatheid fauna of Japan (Crustacea, Anomura). OHMU, 2:33-40.

Baba K, 2005. Deep-sea chirostylid and galatheid Crustaceans (Decapoda: Anomura) from the Indo-Pacific, with a list of species. Galathea Report, 20:1-317.

Baba K, Ahyong ST, Macpherson E, 2011. Morphology of the marine squat lobsters. In: The biology of squat lobsters (Eds., Poore GCB, Ahyong ST, Taylor J). CSIRO Publishing, Melbourne, pp. 1-37.

Baba K, Macpherson E, Lin CW, Chan TY, 2009. Crustacean fauna of Taiwan: squat lobsters (Chirostylidae and Galathei- 
dae). National Taiwan Ocean University, Keelung, pp. 1-311.

Baba K, Macpherson E, Poore GCB, Ahyong ST, Bermudez A, Cabezas P, Lin CW, Nizinski M, Rodrigues C, Schnabel KE, 2008. Catalogue of squat lobsters of the world (Crustacea: Decapoda: Anomura-families Chirostylidae, Galatheidae and Kiwaidae). Zootaxa, 1905:1-220.

De Man JG, 1902. Die von Herrn Professor Kükenthal im Indischen Archipel gesammelten Dekapoden und Stomatopoden. Abhandlungen der Senckenbergischen Naturforschenden Gesellschaft, 25:467-929.

Gosliner TM, Behrens DW, Williams GC, 1996. Coral reef animals of the Indo-Pacific. Sea Challengers, Monterey, pp. 1324.

Henderson JR, 1885. Diagnoses of the new species of Galatheidae collected during the "Challenger" expedition. Annals and Magazine of Natural History, Series 5, 16:407-421.

Kim HS, 1973. Illustrated encyclopedia of fauna and flora of Korea, Vol. 14. Anomura: Brachyura. Samwha Publishing Co., Seoul, pp. 1-649.

Latreille PA, 1802. Histoire naturelle, générale et particulière des Crustacés et des Insectes. Ouvrage faisant suite à l'histoire naturelle générale et particulière, composée par Leclerc de Buffon, et rédigée par C.S. Sonnini, membre de plusieurs sociétés savantes. Familles naturelles des genres. F. DuFart, Paris, pp. 1-467.

Leach WE, 1820. Galatéadées. Dictionnaire des Sciences Naturelles. F. G. Levreault, Paris, pp. 49-56.

Lin CW, Chan TY, Chu KH, 2004. A new squat lobster of the genus Raymunida (Decapoda: Galatheidae) from Taiwan. Journal of Crustacean Biology, 24:149-156.

Macpherson E, Baba K, 2011. Taxonomy of squat lobsters. In: The biology of squat lobsters (Eds., Poore GCB, Ahyong ST, Taylor J). CSIRO Publishing, Melbourne, pp. 39-71.

Macpherson E, Machordom A, 2000. Raymunida, new genus (Decapoda: Anomura: Galatheidae) from the Indian and Pacific Oceans. Journal of Crustacean Biology, 20:253-258.

Macpherson E, Machordom A, 2001. Phylogenetic relationships of species of Raymunida (Decapoda: Galatheidae) based on morphology and mitochondrial cytochrome oxidase sequences, with the recognition of four new species. Journal of Crustacean Biology, 21:696-714.

Osawa M, 2005. The identity of Raymunida elegantissima (Crustacea: Decapoda: Anomura: Galatheidae) and description of a closely related new species from Japan. Species Diversity, 10:85-104.

Osawa M, 2012. Raymunida Macpherson \& Machordom, 2000 (Crustacea: Decapoda: Anomura: Munididae) from the KUMEJIMA 2009 Expedition in the Ryukyu Islands, Japan. Zootaxa, 3367: 134-144.

Poore GCB, 2004. Marine Decapod Crustacea of Southern Australia: a guide to identification with chapter on Stomatopoda by Shane Ahyong. CSIRO Publishing, Melbourne, pp. 1-574.

Samouelle G, 1819. The entomologist's useful compendium; or an introduction to the knowledge of British insects, comprising the best means of obtaining and preserving them, and a description of the apparatus generally used; together with the genera of Linné, and the modern method of arranging the classes Crustacea, Myriapoda, Spiders, Mites and Insects, from their affinities and structure, according to the views of Dr. Leach. Also an explanation of the terms used in entomology; a calendar of the times of appearance and usual situations of near 3,000 species of British insects; with instructions for collecting and fitting up objects for the microscope. Thomas Boys, London, pp. 1-496.

Stimpson W, 1858. Prodromus descriptionis animalium evertebratorum, quae in Expeditione ad Oceanum Pacificum Septentrionalem, a Republica Federata missa, Cadwaladaro Ringgold et Johanne Rodgers Ducibus, observavit et descripsit. Pars VII. Crustacea Anomura. Proceedings of the Academy of Natural Sciences of Philadelphia, 10:225-252. 